\title{
Simultaneous assessment of endothelial function and morphology in the brachial artery using a new semiautomatic ultrasound system
}

\author{
Tomokazu Iguchi ${ }^{1}$, Yasuhiko Takemoto ${ }^{1,2}$, Kenei Shimada ${ }^{1}$, Kenji Matsumoto ${ }^{1}$, Koki Nakanishi ${ }^{1}$, \\ Kenichiro Otsuka $^{1}$, Eiichi Hyodo ${ }^{1}$, Kazuhiro Hirohashi ${ }^{1,2}$, Akira Tahara $^{1,3}$ and Minoru Yoshiyama ${ }^{1}$
}

The accuracy of measurements of the intima-media thickness (IMT) and flow-mediated dilatation (FMD) of the brachial artery made using a new semiautomated ultrasound system and the relationships among those parameters and the Framingham Risk Score (FRS) as a predictor of coronary heart disease (CHD) are unknown. We enrolled 70 subjects, including 47 patients with cardiovascular risk factors and 23 normal healthy volunteers. IMT and FMD were simultaneously measured using a new semiautomated ultrasound system, and the measurements were compared with those obtained manually as a reference standard (study 1). In addition, we enrolled 200 consecutive patients with risk factors but no CHD to examine the relationships among IMT, FMD and the FRS. The optimal cutoff values of FMD and IMT were determined in 200 patients without CHD, and the subjects were classified into four groups. The 10-year Framingham risks for each group were compared (study 2). FMD and IMT measurements made using the new semiautomated ultrasound system showed a good correlation with the measurements determined manually (study 1). Furthermore, FMD and IMT showed a significant correlation with the FRS. The 10-year Framingham risk was markedly higher in group D (FMD $<5.5 \%$ and IMT $>0.3 \mathrm{~mm} ; 19.0 \pm 11.3 \%$; study 2 ). In conclusion, the measurements made using a new semiautomated ultrasound system provided reliable and simultaneous evaluations of IMT and FMD. The combination of IMT and FMD measurements of the brachial artery may be beneficial for risk stratification of patients with cardiovascular risk factors but no CHD.

Hypertension Research (2013) 36, 691-697; doi:10.1038/hr.2013.35; published online 18 April 2013

Keywords: brachial artery; flow-mediated dilatation; intima-media thickness; simultaneous automated measurements

\section{INTRODUCTION}

Flow-mediated dilatation (FMD), which is a functional parameter of the brachial artery, reflects vascular endothelial function. ${ }^{1-3}$ Many studies have shown the usefulness of this parameter in predicting cardiovascular events. ${ }^{4-11}$ Similarly, the intima-media thickness (IMT) of the carotid artery is a predictor of cardiovascular events in various subjects. Recently, the IMT of the brachial artery, a morphologic parameter, has also been associated with risk factors $^{12-14}$ and coronary endothelial function ${ }^{15}$ in patients with coronary heart disease (CHD).

A new ultrasound system with a semiautomatic vessel wall tracking software program, in which A-mode wall tracking and B-mode edge detection methods are performed simultaneously, has been developed recently and has become available in clinical settings. This method provides an automated optimal positioning of the transducer on the brachial artery with a stereotactic arm, displays one longitudinal and two short-axis images of the brachial artery, permits multiple measurements along the vessel wall with simultaneous assessment of FMD and IMT, and is expected to increase the precision of FMD and IMT measurements and decrease observer variability. However, there has been no report evaluating the accuracy of the measurements of lumen diameter, FMD and brachial IMT by this system and software.

This study aimed to: (1) validate the accuracy of the newly developed semiautomated ultrasound system and software program for the measurement of lumen diameter, FMD and IMT compared with the values obtained using conventional manual measurements as a reference standard; and (2) examine the relationships among IMT and FMD, as measured using the new ultrasound system, and clinical variables, biochemical parameters and the Framingham Risk Score (FRS) as predictors of CHD and compare the 10-year Framingham risk among four groups that were classified by the optimal cutoff values of FMD and IMT based on receiver operating characteristic (ROC) curve analyses.

${ }^{1}$ Department of Internal Medicine and Cardiology, Osaka City University Graduate School of Medicine, Osaka, Japan; ${ }^{2}$ Department of Graduate Medical Education and General Practice, Osaka City University Graduate School of Medicine, Osaka, Japan and ${ }^{3}$ Department of Internal Medicine and Cardiology, Asakayama General Hospital, Osaka, Japan Correspondence: Dr Y Takemoto, Department of Internal Medicine and Cardiology, Department of Graduate Medical Education and General Practice, Osaka City University Graduate School of Medicine, 1-4-3, Asahi-machi, Abeno-ku, Osaka 545-8585, Japan.

E-mail: yatakemoto@med.osaka-cu.ac.jp

Received 17 September 2012; revised 8 January 2013; accepted 14 January 2013; published online 18 April 2013 


\section{METHODS}

\section{Study protocols}

Study 1: validation of the software program for measurements of the lumen diameter, FMD and IMT. We consecutively enrolled 70 subjects, including 47 patients (35 men) with cardiovascular risk factors (mean age, $61 \pm 13$ years) and 23 normal healthy volunteers ( $21 \mathrm{men}$ ) with no cardiovascular risk factors (mean age, $25 \pm 4$ years). Hypertension was considered to be systolic blood pressure $\geqslant 140 \mathrm{~mm} \mathrm{Hg}$ and/or diastolic blood pressure $\geqslant 90 \mathrm{~mm} \mathrm{Hg}$ based on the average of two or more readings taken on each of two or more different days; it was also considered to be the current use of antihypertensive drugs. Subjects with plasma low-density lipoprotein cholesterol levels $>140 \mathrm{mg} \mathrm{dl}^{-1}$ or those who were receiving cholesterol-lowering therapy were defined as hypercholesterolemic patients. Patients were regarded as diabetic if they were receiving treatment with insulin or oral hypoglycemic agents or if their hemoglobin Alc levels were $>6.5 \%$. Smokers were defined as subjects who had smoked regularly during the previous 12 months. A history of CHD and a family history of CHD were obtained.

Study 2: examination of the relationships between the FRS and IMT or FMD values obtained using the newly developed ultrasound system and a comparison of 10-year Framingham risk among classified groups. We consecutively enrolled 218 patients with cardiovascular risk factors; of the 218 patients, 18 patients with CHD were excluded. Therefore, correlations between FMD or IMT of the brachial artery and the FRS were examined in 200 patients (patient group; 142 men; mean age, $59 \pm 13$ years) with risk factors but no CHD.

The subjects were classified into three groups according to the values of the brachial IMT, and the 10-year Framingham risk was compared among three groups.

In addition, ROC curve analyses were performed to determine the optimal cutoff values of FMD and IMT. The subjects were classified into four groups according to the cutoff values, and the 10-year Framingham risk was compared among the four groups. The definitions of cardiovascular risk factors were the same as those definitions used in study 1 .

Written informed consent was obtained from all subjects for both studies.

\section{Newly developed ultrasound system}

A new ultrasound system with a semiautomatic vessel wall tracking software program (UNEXEF; Unex, Nagoya, Japan) provided one longitudinal and two short-axis images simultaneously using a newly developed $10 \mathrm{MHz} \mathrm{H}$-type probe (Figure 1). The ultrasound system also provided one processed A-mode line image of the brachial artery (Figure 2) with a stereotactic probe holder, which was used for positioning the transducer at an optimal position on the brachial artery proximal to the bifurcation of the radial and ulnar arteries. Two short-axis images allowed the transducer to remain in the same position.

On the processed A-mode line image, the echo signals reflected by the interfaces between the endothelium and blood on one side and between the blood and endothelium on the other side were identified for the vessel lumen, and their displacement was monitored. After selecting the desired interfaces on the display, the exact position of each interface was determined using the peak point of the A-mode and was tracked continuously. The B-mode edge detection method was automatically used to select the most likely position of the brachial artery on the interface and to maintain positional stability of the A-mode line. The B-mode edge detection method was also designed to automatically maintain the same position of the brachial artery on the interface by adjusting the deviation of the probe position during the periods before and after compression at the forearm to achieve a precise measurement of the vessel lumen. The electrocardiogram was used to detect each $\mathrm{R}$ wave, which allowed the recording of the vessel diameter to be synchronized with the end diastole. The vessel inner diameter at the end diastolic period was automatically and continuously measured for each pulse, and the measurement result was shown on the screen. All images during measurement were stored on hard drive memory for off-line analysis.

\section{Ultrasound assessment of the brachial artery}

All subjects were instructed to fast for at least $12 \mathrm{~h}$; to stop heavy exercise for at least $24 \mathrm{~h}$; to abstain from smoking and the consumption of alcohol, caffeine and antioxidant vitamins for at least $6 \mathrm{~h}$; and to sleep soundly for at least $6 \mathrm{~h}$ the night before testing. If the subjects were premenopausal women, the tests were performed during the phase of the menstrual cycle. All drugs were withheld for at least $12 \mathrm{~h}$ before testing. All subjects were asked to rest in the sitting position in a quiet, air-conditioned and temperature-controlled room $\left(22-25^{\circ} \mathrm{C}\right)$ for $15 \mathrm{~min}$. After the subjects had rested again for at least $15 \mathrm{~min}$ in a supine position in the same room, an ultrasound assessment of the brachial artery was performed between 0700 and $1159 \mathrm{~h}$, according to the guidelines for ultrasound assessment of the FMD of the brachial artery. ${ }^{16}$

One longitudinal image, two short-axis images and one processed A-mode line image of the brachial artery were recorded and stored on the hard drive for off-line measurements. Then, suprasystolic compression (at least $50 \mathrm{~mm} \mathrm{Hg}$ above systolic blood pressure) was performed on the forearm for $5 \mathrm{~min}$, and longitudinal images of the brachial artery were continuously recorded from $0 \mathrm{~s}$ after cuff inflation to $5 \mathrm{~min}$ after cuff release and were stored on the hard drive for off-line assessment.

The lumen diameter of the brachial artery, both at the baseline and at maximum dilatation, and the IMT of the brachial artery at baseline were automatically measured by an examiner blinded to the status and/or diagnoses of the subjects using the software program.

The values of the brachial artery diameter, both at baseline and at maximum dilatation, and the IMT of the brachial artery at baseline were measured manually using electronic calipers by an examiner blinded to the status and/or diagnoses of the subjects. The lumen diameters at both baseline and maximum dilatation were measured as the distance between the center of the near and far wall intima obtained from longitudinal B-mode images of the brachial artery. The lumen diameters were measured at three different sites per image per patient. IMT was assessed at the far wall as the distance between the
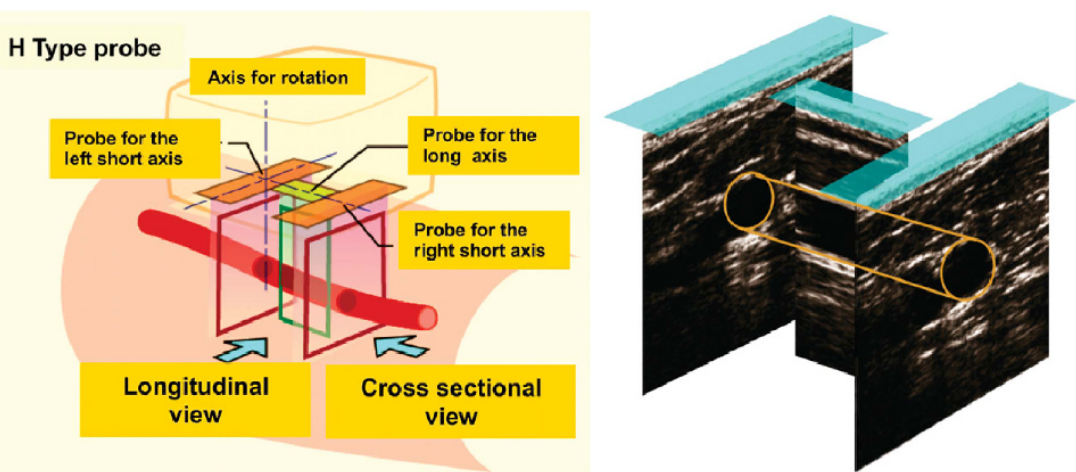

Figure $1 \mathrm{Newly}$ developed $\mathrm{H}$-type probe. The $\mathrm{H}$-type probe provided ultrasound images of one longitudinal and two cross-sectional views (right and left short-axis view) simultaneously. 
lumen-intima and media-adventitia border. IMT measurements were also performed at three sites per image per patient.

\section{Clinical data and FRS}

The medical records of each of the 47 (study 1) and 200 patients (study 2) were comprehensively reviewed for clinical data. The standard clinical definitions of CHD, peripheral artery disease and carotid artery disease were used. The definitions of hypertension, dyslipidemia, diabetes and smoking status were the same as the definitions described above. The FRS was calculated for all patients in study 2 according to the CHD score sheet for men and women. ${ }^{17}$

\section{Statistical analysis}

All values are expressed as the mean \pm s.d. (range) or as frequencies (percentage). Two-sample $t$-tests were used to compare the patients and the normal healthy volunteers. Relationships between values such as the lumen diameter of the brachial artery at baseline and at maximum dilatation and the IMT of the brachial artery at baseline obtained using manual measurements or the software were examined using linear least-squares regression analysis with limits-of-agreement analysis using the Bland and Altman ${ }^{18}$ method. Inter- and intraobserver variability for the lumen diameter of the brachial artery at baseline and at maximum dilatation and the IMT of the brachial artery at baseline obtained using manual measurements or using the software were measured by analyzing 10 randomly selected patients and 5 randomly selected normal healthy volunteers by two independent blinded observers. All results were compared using a linear least-squares regression analysis with limits-ofagreement analysis using the Bland and Altman method. ${ }^{18}$

Univariate and multivariate logistic regression analyses were used to examine associations between variables and IMT or FMD. Statistical analyses were performed using JMP statistical software version 9.0.2 (SAS Institute, Cary, NC, USA). Statistical significance was set at a value of $P<0.05$.

\section{RESULTS}

In study 1, we examined 47 patients with cardiovascular risk factors and 23 normal healthy volunteers. In study 2, 200 patients with cardiovascular risk factors but no $\mathrm{CHD}$ were examined. The characteristics of the subjects in these studies are summarized in Table 1.

Measurements collected manually and using the software Table 2 shows the lumen diameter, FMD and IMT of the brachial artery analyzed manually and using the software. No differences were observed in the values measured manually and using the software.

Table 1 Baseline characteristics

\begin{tabular}{lcc} 
& Study $1(\mathrm{n}=70)$ & Study $2(\mathrm{n}=200)$ \\
\hline Age & $49 \pm 20$ & $59 \pm 13$ \\
Men, $n(\%)$ & $56(80)$ & $142(71)$ \\
Smoking, $n(\%)$ & $15(21)$ & $104(52)$ \\
Hypertension, $n(\%)$ & $24(34)$ & $93(47)$ \\
Diabetes, $n(\%)$ & $11(16)$ & $66(33)$ \\
Dyslipidemia, $n(\%)$ & $21(30)$ & $130(65)$ \\
History of CHD, $n(\%)$ & $6(9)$ & $0(0)$
\end{tabular}

Abbreviation: CHD, coronary heart disease.

Values are mean \pm s.d. or frequencies (percentage)

a
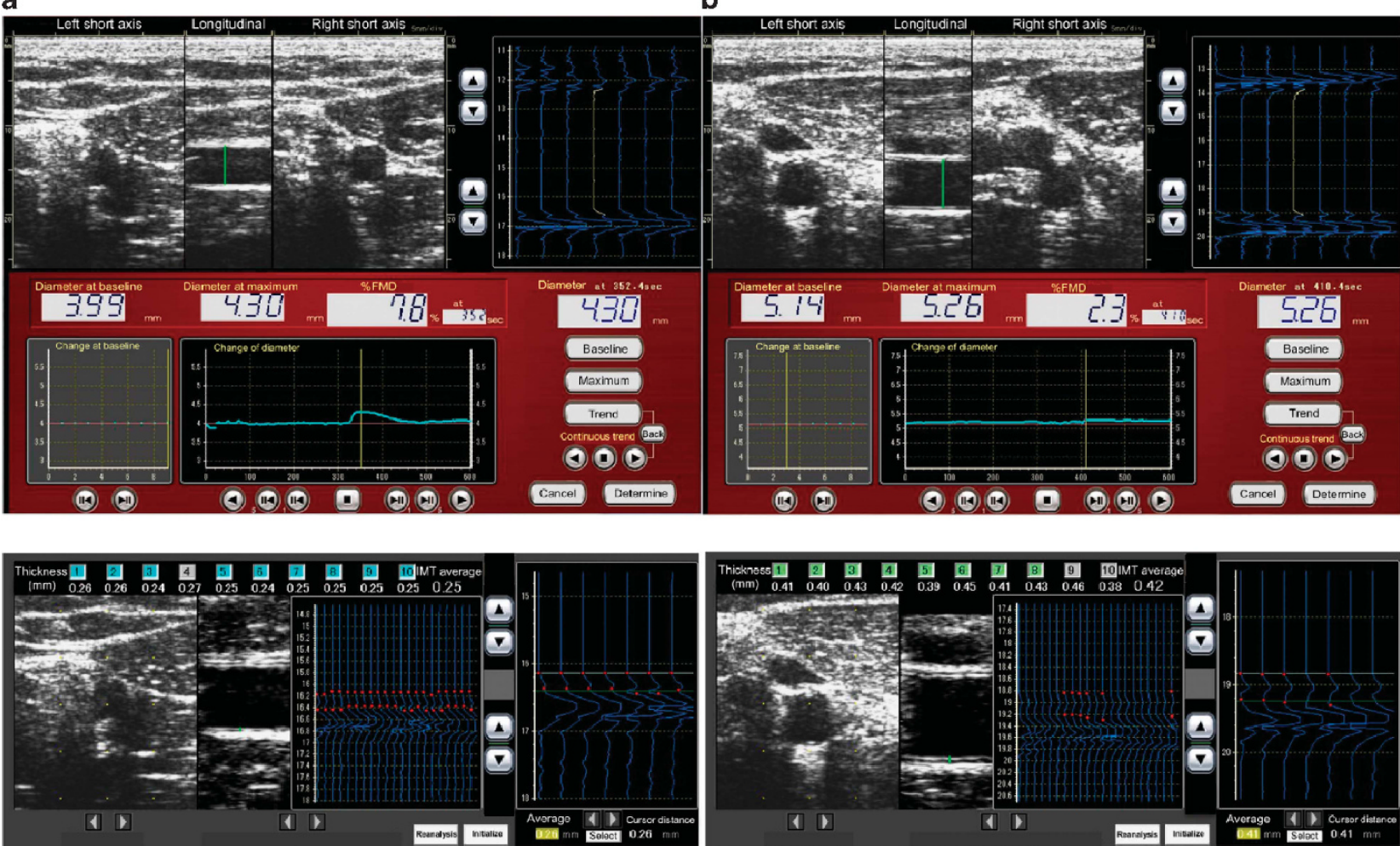

Figure 2 Representative images of flow-mediated dilatation (FMD) and intima-media thickness (IMT) of the brachial artery. (a) Representative image of normal FMD and a thin IMT of the brachial artery. This subject had one atherosclerotic risk factor. The result of the FMD measurement (a; upper image) was $7.8 \%$, and that of the brachial IMT (a; lower image) was $0.25 \mathrm{~mm}$. (b) Representative image of impaired FMD and a thick brachial IMT. This subject had multiple atherosclerotic risk factors (smoking habits, hypertension and dyslipidemia). The result of the FMD measurement (b; upper image) was $2.3 \%$, and that of the brachial IMT (b; lower image) was $0.42 \mathrm{~mm}$. 
Lumen diameters of the brachial artery at baseline and at maximum dilatation measured using the software correlated well with those measured manually (at baseline, $r=0.999, P<0.0001$, mean difference $=0.020$, s.d. $=0.033$; at maximum dilatation, $r=0.986, P<0.0001$, mean difference $=0.029$, s.d. $=0.028$ ). A good correlation was observed for FMD values obtained using the software and those measured manually $(r=0.976, \quad P<0.0001$, mean difference $=0.153$, s.d. $=0.747$; Figure $3 \mathrm{a})$. A good correlation was observed between the IMT of the brachial artery measured using the software and IMT measured manually $(r=0.934, P<0.0001$, mean difference $=0.0006$, s.d. $=0.021$; Figure $3 \mathrm{~b}$ ).

\section{Intra- and interobserver variability tests}

The intraobserver correlation coefficients for the lumen diameter measurements at baseline, lumen diameter measurements at maximum dilatation and IMT measurements taken manually were 0.999 $(P<0.0001$, mean difference $=0.021$, s.d. $=0.016), 0.998(P<0.0001$, mean difference $=0.005$, s.d. $=0.031)$ and $0.966(P<0.0001$, mean difference $=0.002$, s.d. $=0.016$ ), respectively. The interobserver correlation coefficients for the lumen diameter measurements at baseline, lumen diameter measurements at maximum dilatation and IMT measurements taken manually were $0.998 \quad(P<0.0001$, mean difference $=0.010$, s.d. $=0.033), 0.999 \quad(P<0.0001$, mean

Table 2 FMD and IMT of the brachial artery parameters

\begin{tabular}{lccc}
\hline & Software & Manual & P-value \\
\hline Diameter at baseline (mm) & $4.06 \pm 0.62$ & $4.04 \pm 0.62$ & 0.85 \\
Diameter at maximum (mm) & $4.24 \pm 0.60$ & $4.22 \pm 0.60$ & 0.78 \\
FMD (\%) & $4.64 \pm 3.04$ & $4.49 \pm 3.31$ & 0.78 \\
Brachial IMT (mm) & $0.27 \pm 0.06$ & $0.27 \pm 0.06$ & 0.95 \\
\hline
\end{tabular}

Abbreviations: FMD, flow-mediated dilatation; IMT, intima-media thickness. Values are mean \pm s.d. difference $=0.010$, s.d. $=0.020)$ and $0.965 \quad(P<0.0001$, mean difference $=0.014$, s.d. $=0.024)$, respectively.

\section{Relationship among IMT, FMD and FRS}

In study 2, univariate analysis showed that FMD was significantly associated with brachial IMT $(r=-0.356, P<0.0001)$, brachial artery diameter at baseline $(r=-0.303, P<0.0001)$, age $(r=-0.233$, $P<0.0001)$ and sex $(r=0.160, P=0.02)$. In addition, univariate analysis showed that IMT was significantly associated with FMD $(r=-0.356, P<0.0001)$, age $(r=0.345, P<0.0001)$, brachial artery diameter at baseline $(r=0.326, P<0.0001)$, sex $\quad(r=0.252$, $P=0.0002)$, systolic blood pressure $(r=0.208, P=0.002)$, estimated glomerular filtration rate $(r=-0.196, P=0.004)$, waist circumference $(r=0.152, P=0.030)$ and hemoglobin Alc level $(r=0.150$, $P=0.032$ ) in 200 patients with risk factors but no CHD (Table 3). Multivariate analysis showed that FMD correlated independently with brachial artery diameter, brachial IMT and age (Table 3). In addition, the IMT correlated independently with age, brachial artery diameter at baseline and FMD (Table 3). The FMD and IMT of the brachial artery significantly correlated with the FRS $(r=-0.279, P<0.0001$ and $r=0.318, P<0.0001$, respectively). Furthermore, the multivariate model that included sex, brachial artery diameter at baseline, FMD and brachial IMT revealed that the FRS correlated independently with brachial IMT, FMD and sex (Table 4).

\section{The 10-year Framingham risk}

The subjects were separated into three groups according to the values of the brachial IMT as follows: group L $(n=84)$, IMT $\leqslant 0.3 \mathrm{~mm}$; group $\mathrm{M}(n=94), 0.3 \mathrm{~mm}<\mathrm{IMT} \leqslant 0.4 \mathrm{~mm}$; and group $\mathrm{H}(n=22)$, IMT $>0.4 \mathrm{~mm}$. The 10 -year Framingham risk in each group was compared among the three groups. The 10-year CHD risk calculated from the Framingham risk score was markedly higher in group $\mathrm{H}$ $(n=22 ; 22.3 \pm 11.8 \%)$ than in group $\mathrm{L}(<0.3 \mathrm{~mm}, n=84$; $11.8 \pm 9.5 \%, \quad P<0.0001) \quad$ or group $\mathrm{M} \quad(0.3-0.4 \mathrm{~mm}, \quad n=94$;
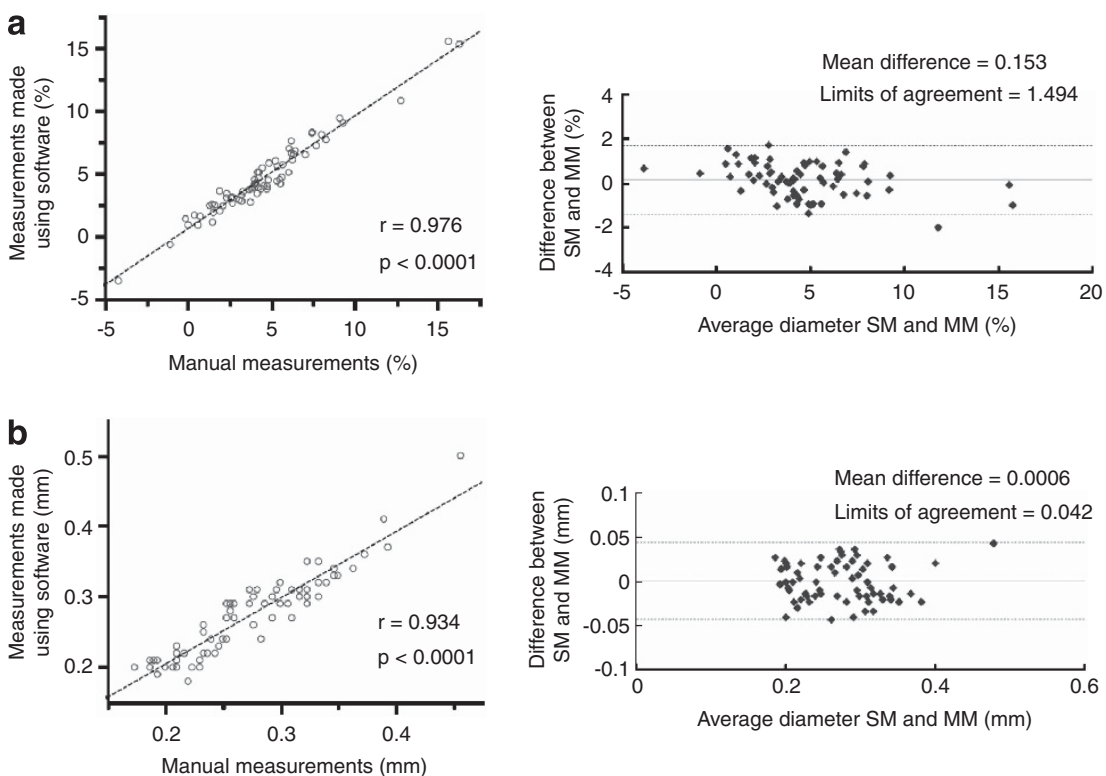

Figure 3 Comparison of flow-mediated dilatation and intima-media thickness of the brachial artery measured manually and using the software. The graphs on the left show the correlations between the measurements made using the software (SM) and manual measurements (MM) (a; flow-mediated dilatation, and $\mathbf{b}$; intima-media thickness of the brachial artery). The $R$-values represent correlation coefficients. The graphs on the right show the Bland and Altman plots for the two methods. The straight lines represent the mean differences between the two methods, and the dotted lines represent the limits of agreements (2 s.d.). A full color version of this figure is available at the Hypertension Research journal online. 
Table 3 Correlation between FMD, IMT of the brachial artery and clinical variables

\begin{tabular}{|c|c|c|c|c|c|c|}
\hline & \multicolumn{3}{|c|}{$F M D$} & \multicolumn{3}{|c|}{ Brachial IMT } \\
\hline & $r$ & P-value & ${ }^{*}$ Adjusted $\mathrm{P}$ & $r$ & $\mathrm{P}$-value & ${ }^{*}$ Adjusted $\mathrm{P}$ \\
\hline Age & -0.233 & 0.0005 & 0.01 & 0.345 & $<0.0001$ & 0.0003 \\
\hline Sex & 0.160 & 0.02 & 0.53 & 0.252 & 0.0002 & 0.23 \\
\hline BMI & -0.028 & 0.68 & - & 0.108 & 0.11 & - \\
\hline Waist & 0.052 & 0.46 & - & 0.152 & 0.03 & 0.49 \\
\hline LC & 0.029 & 0.56 & - & 0.042 & 0.56 & - \\
\hline Smoking & -0.121 & 0.07 & - & 0.031 & 0.65 & - \\
\hline Systolic BP & -0.115 & 0.09 & - & 0.208 & 0.002 & 0.12 \\
\hline Diastolic BP & -0.017 & 0.81 & - & 0.127 & 0.06 & - \\
\hline eGFR & 0.081 & 0.23 & - & -0.196 & 0.004 & 0.83 \\
\hline LDL & 0.074 & 0.28 & - & -0.068 & 0.32 & - \\
\hline HDL & 0.047 & 0.49 & - & -0.091 & 0.18 & - \\
\hline Triglyceride & -0.001 & 0.98 & - & 0.017 & 0.81 & - \\
\hline $\mathrm{HbAlc}$ & -0.095 & 0.17 & - & 0.150 & 0.03 & 0.09 \\
\hline HOMA-IR & 0.068 & 0.38 & - & 0.078 & 0.31 & - \\
\hline BA diameter & -0.303 & $<0.0001$ & 0.0003 & 0.326 & $<0.0001$ & 0.01 \\
\hline FMD & - & - & - & -0.356 & $<0.0001$ & 0.02 \\
\hline Brachial IMT & -0.356 & $<0.0001$ & 0.002 & - & - & - \\
\hline
\end{tabular}

Abbreviations: BA, brachial artery; BMI, body mass index; BP, blood pressure; eGFR, estimated glomerular filtration rate; FMD, flow-mediated dilatation; HbAlc, hemoglobin Alc; HDL, highdensity lipoprotein; HOMA-IR, homeostasis model assessment as an index of insulin resistance; IMT, intima-media thickness; LC, lower leg circumference; LDL, low-density lipoprotein. $r$ means correlation coefficient. *Adjusted $P$-values are $P$-values calculated from multiple linear regression analyses.

Table 4 Multivariate analysis for relating to Framingham risk score

\begin{tabular}{lcc}
\hline & F-value & *P-value \\
\hline Flow-mediated dilatation & 8.50 & 0.004 \\
Brachial intima-media thickness & 16.03 & $<0.0001$ \\
Male sex & 7.82 & 0.006 \\
Brachial artery diameter & 0.46 & 0.50
\end{tabular}

${ }^{*} P$-values are calculated from multiple linear regression analysis except for component factors of Framingham risk score.

$15.9 \pm 10.5 \%, P=0.01$; Figure 4). ROC analyses were performed for predicting the 10-year Framingham risk of not less than $10 \%$. Optimal cutoff values of FMD (5.5\%) and IMT $(0.3 \mathrm{~mm})$ were determined using the ROC curve analyses, and the subjects were classified into four groups as follows: group A $(n=55), \mathrm{FMD} \geqslant 5.5 \%$ and IMT $\leqslant 0.3 \mathrm{~mm}$; group $\mathrm{B}(n=23), \mathrm{FMD} \geqslant 5.5 \%$ and IMT $>0.3 \mathrm{~mm}$; group C $(n=42), \mathrm{FMD}<5.5 \%$ and IMT $\leqslant 0.3 \mathrm{~mm}$; and group D $(n=80)$, FMD $<5.5 \%$ and IMT $>0.3 \mathrm{~mm}$. The 10 -year Framingham risk was markedly higher in group D $(19.0 \pm 11.3 \%)$ than in group A $(11.0 \pm 10.2 \%, P<0.0001)$, group B $(12.9 \pm 9.7 \%$, $P=0.01)$ or group C $(13.2 \pm 8.2 \%, P=0.003$; Figure 5$)$.

\section{DISCUSSION}

Our data show that measurements made using a novel semiautomatic vessel wall tracking system provided reliable simultaneous evaluations of lumen diameters of the brachial artery, both at baseline and at maximum dilatation, and of the IMT of the brachial artery. In addition, the IMT of the brachial artery in patients with cardiovascular risk factors correlated independently with FMD, age and brachial artery diameter at baseline. Furthermore, the IMT of the brachial artery was associated with the FRS.

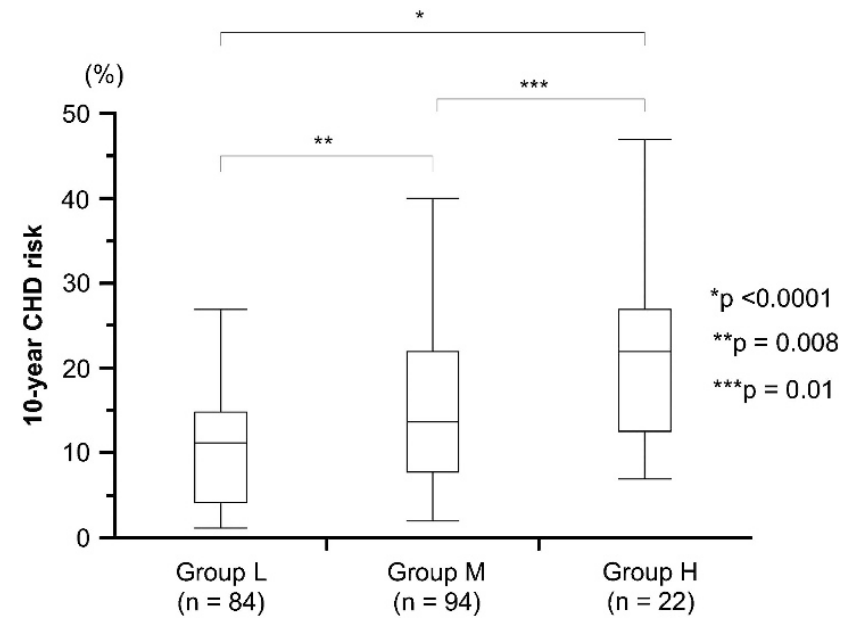

Figure 4 Comparison of the 10-year Framingham risk score among three groups divided by the values of the brachial intima-media thickness (IMT). The 10-year coronary heart disease (CHD) risk score calculated from the Framingham Risk score was markedly higher in group $\mathrm{H}$ (brachial IMT $>0.4 \mathrm{~mm}, n=22 ; 22.3 \pm 11.8 \%$ ) than in group $\mathrm{L}$ (brachial IMT $\leqslant 0.3 \mathrm{~mm}$, $n=84 ; 11.8 \pm 9.5 \%, P<0.0001)$ or group $\mathrm{M}(0.3 \mathrm{~mm}<$ brachial IMT $\leqslant 0.4, n=94 ; 15.9 \pm 10.5 \%, P=0.01)$.

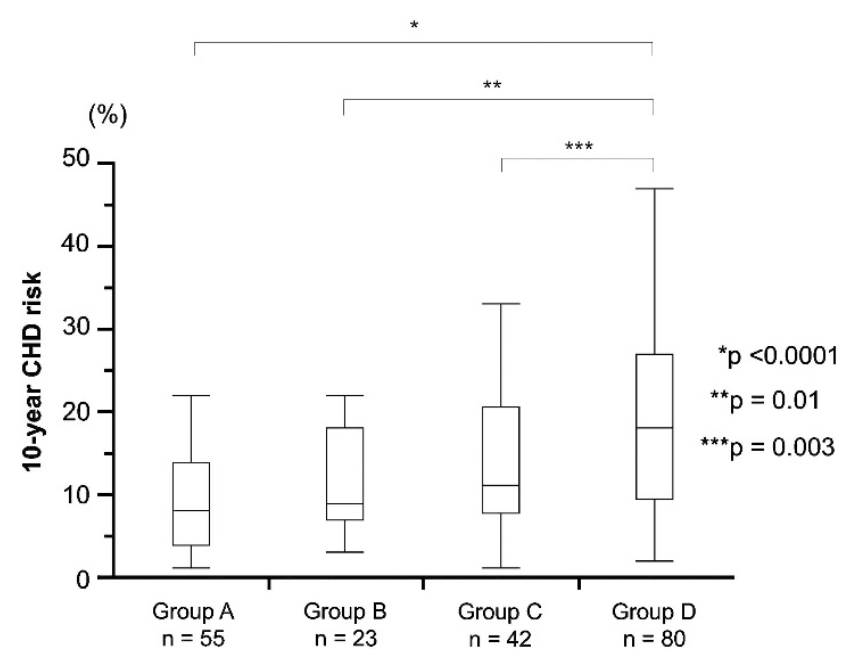

Figure 5 Comparison of the 10-year Framingham risk among four groups divided by the optimal cutoff values of flow-mediated dilatation (FMD) and arterial intima-media thickness (IMT) of the brachial artery. The subjects with risk factors but no coronary heart disease ( $\mathrm{CHD}, n=200)$ were classified into four groups according to the optimal cutoff values of FMD $(5.5 \%)$ and IMT $(0.3 \mathrm{~mm})$ as follows: group $A(n=55)$, FMD $\geqslant 5.5 \%$ and IMT $\leqslant 0.3 \mathrm{~mm}$; group $\mathrm{B}(n=23), \mathrm{FMD} \geqslant 5.5 \%$ and IMT $>0.3 \mathrm{~mm}$; group $\mathrm{C}(n=42), \mathrm{FMD}<5.5 \%$ and IMT $\leqslant 0.3 \mathrm{~mm}$; and group $\mathrm{D}(n=80)$, FMD $<5.5 \%$ and IMT $>0.3 \mathrm{~mm}$. The 10 -year Framingham risk was markedly higher in group D.

Although IMT measurements of the carotid artery have been widely adopted in clinical research and practice, ${ }^{19-23}$ limited data are available regarding the use of IMT measurements of the brachial artery. In addition, the IMT and FMD have been measured manually in the majority of previous studies, and these measurements were time consuming and subjective. Therefore, the development of an objective and easy method for assessing the IMT and FMD of the brachial artery is desirable. The measurements made using the novel 
system in the present study allowed for real-time and objective assessments of the IMT and FMD (Figure 2). Most of the systems in previous investigations relied on the initial manual identification of the near and far walls and were not designed for continuous frame analysis, which is necessary to determine the time course of the response and maximum dilatation. ${ }^{24}$ The software program used with the novel system provided one longitudinal image, two short-axis images and one processed A-mode line image of the brachial artery with a stereotactic probe holder. Two short-axis images allowed the probe to be maintained at the same position because any deviations in the probe position could be relatively easily observed. The exact positions of the selected interfaces between the endothelium and blood on one side and between the blood and endothelium on the other side were determined using the peak point of the A-mode and were tracked continuously with the simultaneous B-mode edge detection method. Therefore, the software program using the system provided adequate images for continuous frame analysis and enabled us to perform reliable and quick evaluations of both the IMT and FMD of the brachial artery.

Measurements made using this novel system had not yet been appropriately validated against those made using traditional manual analyses; however, our study showed that the lumen diameters and IMT of the brachial artery measured using this software correlated well with the manual measurements of these parameters. Indeed, the average values of the IMT of the brachial artery in patients with risk factors and in normal healthy volunteers were similar to those reported in previous studies. ${ }^{12,13}$ Atherosclerotic changes in the brachial artery are generally diffuse in contrast to advanced lesions in the carotid artery, which suggests the advantages of using brachial IMT as a more sensitive indicator of systemic atherosclerotic risk. This newly developed software enabled us to perform instant, simultaneous and objective measurements of the IMT and FMD of the brachial artery.

Our study showed that IMT measurements of the brachial artery correlated independently with FMD, which has been well recognized as a useful marker for predicting cardiovascular events. Furthermore, we examined the relationships among the FMD, IMT and FRS. Park et al. ${ }^{25}$ reported that the age-adjusted FRS was significantly correlated with FMD in 138 patients with stable angina. Our data showed that both IMT and FMD were significantly associated with the FRS and that the 10-year Framingham risk of group M (brachial IMT $>0.3 \mathrm{~mm}$ ) was significantly increased compared with that of group L (brachial IMT $\leqslant 0.3 \mathrm{~mm}$; Figure 4 ). In addition, Figure 5 shows that the 10-year Framingham risk of group C (FMD $<5.5 \%$ and IMT $\leqslant 0.3 \mathrm{~mm}$ ) was not significantly decreased compared with that of group A (FMD $\geqslant 5.5 \%$ and IMT $\leqslant 0.3 \mathrm{~mm}$ ) when the subjects were classified by optimal cutoff values of FMD and IMT on the basis of the ROC curve analyses. These results suggest that the combination of IMT and FMD measurements may be more beneficial than a single measurement of FMD to for risk stratification of patients with risk factors but no CHD. Furthermore, in a previous study, the brachial, common carotid and left anterior descending coronary arteries were examined at autopsy, and atherosclerosis was reported to occur commonly in the brachial artery and to be correlated with the presence and severity of coronary and carotid atherosclerosis. ${ }^{26}$ These results suggest that IMT measurements of the brachial artery may be a promising predictor of atherosclerosis.

\section{Study limitations}

Although the FRS has been adopted as a surrogate for clinical outcomes in several previous studies in Japanese patients, there are no well-established data indicating that the FRS is related to clinical outcomes for Japanese patients. The IMT of the carotid artery has been extensively shown to be a surrogate measure of atherosclerosis associated with cardiovascular outcomes; however, the relationship between the IMT of the brachial artery and cardiovascular outcomes has not been completely investigated in this present study. ${ }^{19-23}$ Additional clinical studies regarding the association between IMT of the brachial artery and cardiovascular outcomes are warranted.

Although previous studies have demonstrated relationships between the IMT of the carotid artery and FMD, ${ }^{27-29}$ the association between the IMT values of the brachial and carotid arteries has not been investigated in this study. Further investigations are required to determine the relationship between brachial arterial and carotid arterial IMT.

\section{CONCLUSIONS}

The measurements made using a novel semiautomatic vessel walltracking system in this study provided reliable and simultaneous evaluations of the IMT and FMD of the brachial artery. The combination of measurements of the IMT and FMD of the brachial artery may be beneficial to for risk stratification of patients with risk factors but no CHD.

\section{CONFLICT OF INTEREST}

The authors declare no conflict of interest.

1 Smiesko V, Kozik J, Dolezel S. Role of endothelium in the control of arterial diameter by blood flow. Blood Vessels 1985; 22: 247-251.

2 Pohl U, Holtz J, Busse R, Bassenge E. Crucial role of endothelium in the vasodilator response to increased flow in vivo. Hypertension 1986; 8: 37-44.

3 Celermajer DS, Sorensen KE, Gooch VM, Spiegelhalter DJ, Miller OI, Sullivan ID, Lloyd JK, Deanfield JE. Non-invasive detection of endothelial dysfunction in children and adults at risk of atherosclerosis. Lancet 1992; 340: 1111-1115.

4 Lieberman EH, Gerhard MD, Uehata A, Selwyn AP, Ganz P, Yeung AC, Creager MA Flow-induced vasodilation of the human brachial artery is impaired in patients $<40$ years of age with coronary artery disease. Am J Cardiol 1996; 78: 1210-1214.

5 Chan SY, Mancini GB, Kuramoto L, Schulzer M, Frohlich J, Ignaszewski A. The prognostic importance of endothelial dysfunction and carotid atheroma burden in patients with coronary artery disease. J Am Coll Cardiol 2003; 42: 1037-1043.

6 Huang AL, Silver AE, Shvenke E, Schopfer DW, Jahangir E, Titas MA, Shpilman A, Menzoian JO, Watkins MT, Raffetto JD, Gibbons G, Woodson J, Shaw PM, Dhadly M, Eberhardt RT, Keaney JF Jr, Gokce N, Vita JA. Predictive value of reactive hyperemia for cardiovascular events in patients with peripheral arterial disease undergoing vascular surgery. Arterioscler Thromb Vasc Biol 2007; 27: 2113-2119.

7 Hu R, Wang WQ, Lau CP, Tse HF. Gender differences on brachial flow-mediated dilation and carotid intima-media thickness for prediction of spontaneous cardiovascular events. Clin Cardiol 2008; 31: 525-530.

8 Kitta Y, Obata JE, Nakamura T, Hirano M, Kodama Y, Fujioka D, Saito Y, Kawabata K, Sano K, Kobayashi T, Yano T, Nakamura K, Kugiyama K. Persistent impairment of endothelial vasomotor function has a negative impact on outcome in patients with coronary artery disease. J Am Coll Cardiol 2009; 53: 323-330.

9 Yeboah J, Folsom AR, Burke GL, Johnson C, Polak JF, Post W, Lima JA, Crouse JR, Herrington DM. Predictive value of brachial flow-mediated dilation for incident cardiovascular events in a population-based study: the multi-ethnic study of atherosclerosis. Circulation 2009; 120: 502-509.

10 Lerman A, Zeiher AM. Endothelial function: cardiac events. Circulation 2005; 111 363-368.

11 Kirma C, Akcakoyun M, Esen AM, Barutcu I, Karakaya O, Saglam M, Kargin R, Turkmen M, Boztosun B, Izgi A, Sonmez K. Relationship between endothelial function and coronary risk factors in patients with stable coronary artery disease. Circ J 2007; 71: 698-702.

12 Frick M, Schwarzacher SP, Alber HF, Rinner A, Ulmer $\mathrm{H}$, Pachinger $\mathrm{O}$, Weidinger $\mathrm{F}$. Morphologic rather than functional or mechanical sonographic parameters of the brachial artery are related to angiographically evident coronary atherosclerosis. J Am Coll Cardiol 2002; 40: 1825-1830.

13 Weidinger F, Frick M, Alber HF, Ulmer H, Schwarzacher SP, Pachinger O. Association of wall thickness of the brachial artery measured with high-resolution ultrasound with risk factors and coronary artery disease. Am J Cardiol 2002; 89: 1025-1029.

14 Esen AM, Barutcu I, Acar M, Degirmenci B, Kaya D, Turkmen M, Melek M, Onrat E, Esen OB, Kirma C. Effect of smoking on endothelial function and wall thickness of brachial artery. Circ J 2004; 68: 1123-1126. 
15 Frick M, Suessenbacher A, Alber HF, Dichtl W, Ulmer H, Pachinger O, Weidinger F. Prognostic value of brachial artery endothelial function and wall thickness. J Am Coll Cardiol 2005; 46: 1006-1010.

16 Corretti MC, Anderson TJ, Benjamin EJ, Celermajer D, Charbonneau F, Creager MA, Deanfield J, Drexler H, Gerhard-Herman M, Herrington D, Vallance P, Vita J, Vogel R. Guidelines for the ultrasound assessment of endothelial-dependent flow-mediated vasodilation of the brachial artery: a report of the International Brachial Artery Reactivity Task Force. J Am Coll Cardiol 2002; 39: 257-265.

17 Wilson PWF, D'Agostino RB, Levy D, Belanger AM, Silbershatz H, Kannel WB. Prediction of coronary heart disease using risk factor categories. Circulation 1998; 97: 1837-1847.

18 Bland JM, Altman DG. Statistical methods for assessing agreement between two methods of clinical measurement. Lancet 1986; 1: 307-310.

19 Chambless LE, Heiss G, Folsom AR, Rosamond W, Szklo M, Sharrett AR, Clegg LX. Association of coronary heart disease incidence with carotid arterial wall thickness and major risk factors: the Atherosclerosis Risk in Communities (ARIC) Study, 1987-1993. Am J Epidemiol 1997; 146: 483-494.

20 O'Leary DH, Polak JF, Kronmal RA, Manolio TA, Burke GL, Wolfson SK Jr. Carotidartery intima and media thickness as a risk factor for myocardial infarction and stroke in older adults. Cardiovascular Health Study Collaborative Research Group. N Eng/ J Med 1999; 340: 14-22.

21 Iglesias del Sol A, Bots ML, Grobbee DE, Hofman A, Witteman JC. Carotid intimamedia thickness at different sites: relation to incident myocardial infarction; The Rotterdam Study. Eur Heart J 2002; 23: 934-940.
22 Rosvall M, Janzon L, Berglund G, Engstrom G, Hedblad B. Incident coronary events and case fatality in relation to common carotid intima-media thickness. $J$ Intern Med 2005; 257: 430-437.

23 Lorenz MW, von Kegler S, Steinmetz H, Markus HS, Sitzer M. Carotid intima-media thickening indicates a higher vascular risk across a wide age range: prospective data from the Carotid Atherosclerosis Progression Study (CAPS). Stroke 2006; 37: 87-92.

24 Stadler RW, Karl WC, Lees RS. New methods for arterial diameter measurement from B-mode images. Ultrasound Med Biol 1996; 22: 25-34.

25 Park K-H, Kim M-K, Kim H-S, Park WJ, Cho G-Y, Choi Y-J. Clinical significance of Framingham risk score, flow-mediated dilation and pulse wave velocity in patients with stable angina. Circulation Journal 2011; 75: 1177-1183.

26 Sorensen KE, Kristensen IB, Celermajer DS. Atherosclerosis in the human brachial artery. J Am Coll Cardiol 1997; 29: 318-322.

27 Hashimoto M, Eto M, Akishita M, Kozaki K, Ako J, lijima K, Kim S, Toba K, Yoshizumi M, Ouchi Y. Correlation between flow-mediated vasodilatation of the brachial artery and intima-media thickness in the carotid artery in men. Arterioscler Thromb Vasc Biol 1999; 19: 2795-2800.

28 Juonala M, Viikari JS, Laitinen T, Marniemi J, Helenius H, Ronnemaa T, Raitakari OT. Interrelations between brachial endothelial function and carotid intima-media thickness in young adults: the cardiovascular risk in young Finns study. Circulation 2004; 110: 2918-2923.

29 Yan RT, Anderson TJ, Charbonneau F, Title L, Verma S, Lonn E. Relationship between carotid artery intima-media thickness and brachial artery flow-mediated dilation in middle-aged healthy men. J Am Coll Cardiol 2005; 45: 1980-1986. 